\title{
THE EFFECT OF LACTULOSE ON THE FAECAL FLORA OF PATIENTS WITH HEPATIC ENCEPHALOPATHY
}

\author{
Angela Vince, R. Zeegen, J. E. Drinkwater, F. O'Grady \\ AND A. M. DAwSON \\ St Bartholomew's Hospital, London ECIA $7 B E$
}

Several workers (Fung and Khoo, 1968; Bircher et al., 1969; Elkington, Floch and Conn, 1969; Ma, McLeod and Blackburn, 1969; Zeegen et al., 1970) have found lactulose therapy beneficial in the treatment of hepatic encephalopathy which is thought to result, at least in part, from cerebral intoxication caused by the failure of a damaged or by-passed liver to continue the normal detoxification of substances such as ammonia elaborated by bacteria in the gut. Lactulose is a synthetic disaccharide that is not hydrolysed by the disaccharidases of the small intestine of man (Dahlqvist and Gryboski, 1965). It passes unabsorbed into the ascending colon, where it is split by the action of bifidobacteria, lactobacilli and faecal streptococci to yield mainly lactic and acetic acids (Hoffmann et al., 1964), the accumulation of which causes the colonic $p \mathrm{H}$ to fall and fermentative diarrhoea to develop.

The present study evaluates the effect of lactulose on the faecal flora of the patients studied by Zeegen et al. (1970) and examines the possibility that the changes observed were due solely to purgation.

\section{MATERIALS AND METHODS}

Five patients, three men and two women, were studied in hospital. All had suffered from periodic encephalopathy over periods varying from a few months to several years. Each patient was studied during an initial stabilisation period of constant protein intake ( 70 or $80 \mathrm{~g}$ per day) and subsequently during successive periods of administration of lactulose or magnesium sulphate. Lactulose was given first in three cases and magnesium sulphate first in the other two. Three patients were given lactulose therapy twice. Neomycin was given over a further period of 5 days to one patient (no. 5). The dose of lactulose was adjusted to produce two to three soft or semi-formed stools a day: usually between 100 and $150 \mathrm{ml}$ of syrup ( $50 \%$ lactulose) in divided doses three or four times a day was required. Magnesium sulphate was used in doses adjusted to produce a similar quantity of stool: usually $15 \mathrm{ml}$ of a solution containing $6 \mathrm{~g}$ of magnesium sulphate twice or three times daily.

Bacteriological examination of faeces. Fresh specimens were obtained daily or at regular intervals and were examined immediately upon arrival at the laboratory as described previously (Hamilton et al., 1970; Zeegen et al., 1970). The average period over which each patient was studied was 50 days and a total of 160 specimens was examined.

Expression of results. The results were analysed by a slightly modified version of Goldsmith's (1965) autocorners computer programme. This takes into account the fact that considerable spontaneous variation in faecal bacterial counts may be found in the same person on successive days. The deviation of each individual reading from the mean of the whole series was calculated and its significance assessed by application of the Student " $t$ "

Received 30 May 1973; accepted 12 June 1973.

J. MED. MICROBIOL.—VOL. 7 (1974) 
test at the $1 \%$ level. A change in level was printed only if significant differences were maintained for four or more successive readings.

\section{RESULTS}

The table lists the highest mean counts recorded for individual organisms in each patient during the various treatments. A typical computer plot which shows the significant increases and decreases in the counts of different groups

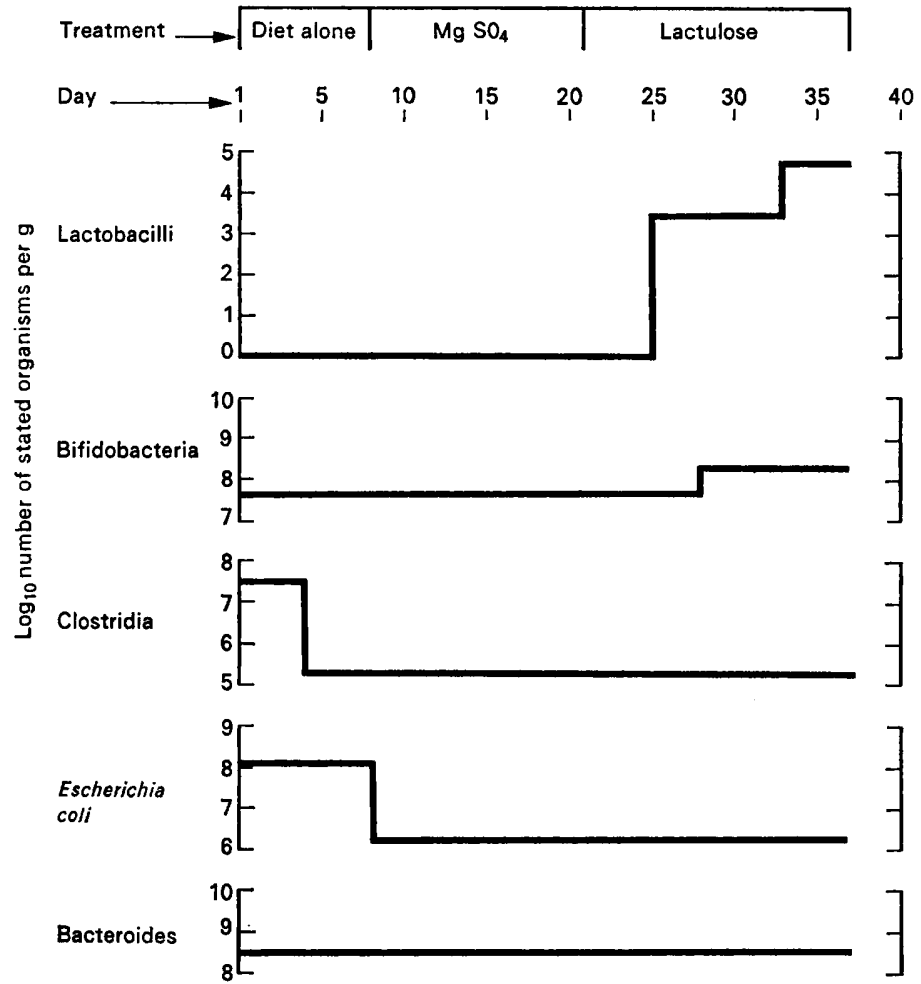

FigURE.-Mean counts of lactobacilli, bifidobacteria, clostridia, Esch. coli and Bacteroides spp., as indicated by computer analysis, during successive periods of treatment of one patient on a constant 70-g protein intake with (a) diet alone, (b) diet + magnesium sulphate, (c) diet + lactulose.

of organisms over the various treatment periods for one patient is shown in the figure. Usually there was a single mean value that was maintained during each treatment, but occasionally significant changes occurred within a treatment period-as shown in the figure where two significant mean values for lactobacilli were obtained during lactulose treatment.

During the stabilisation period no significant increase occurred in the count of any organism. The highest mean aerobic lactobacillus count during lactulose therapy exceeded that of the stabilisation period in three patients (nos. 1, 2 and 3), two of whom (nos. 1 and 2) responded clinically to lactulose. Among the three patients who showed significant increases in lactobacillus counts while receiving lactulose, the counts at the end of the period of treatment 


\section{TABLE}

Highest mean counts of lactobacilli, bifidobacteria, clostridia, enterococci, Escherichia coli and Bacteroides spp. as recorded by computer analysis when five patients with hepatic encephalopathy were treated with (i) diet alone, (ii) diet + lactulose, and (iii) diet + magnesium sulphate. Counts above the broken line in each group are from patients who responded clinically to lactulose

\begin{tabular}{|c|c|c|c|c|}
\hline \multirow{2}{*}{$\begin{array}{l}\text { Group of } \\
\text { organisms }\end{array}$} & \multirow{2}{*}{$\begin{array}{l}\text { Patient } \\
\text { no. }\end{array}$} & \multicolumn{3}{|c|}{$\begin{array}{l}\text { Highest mean count of stated organism } \\
\text { per } \mathrm{g} \text { of faeces in patients treated by }\end{array}$} \\
\hline & & diet alone & lactulose & magnesium sulphate \\
\hline Lactobacilli & $\begin{array}{l}1 \\
2 \\
3 \\
4 \\
5\end{array}$ & $\begin{array}{c}9.0 \times 10^{7} \\
0 \\
-\frac{0}{0}- \\
5 \cdot 3 \times 10^{6} \\
9.9 \times 10^{7}\end{array}$ & $\begin{array}{l}9 \cdot 9 \times 10^{9} \\
7 \cdot 7 \times 10^{6} \\
--7.6 \times 10^{4} \\
6.6 \times 10^{6} \\
2 \cdot 3 \times 10^{7} \\
8 \cdot 2 \times 10^{7}\end{array}$ & $-\frac{\begin{array}{l}8.5 \times 10^{6} \\
4.0 \times 10^{4}\end{array}}{-0}---$ \\
\hline Bifidobacteria & $\begin{array}{l}1 \\
2 \\
3 \\
4 \\
5\end{array}$ & $\begin{array}{c}2.0 \times 10^{8} \\
5.0 \times 10^{7} \\
-\frac{-}{6.2 \times 10^{7}} \\
1.0 \times 10^{7} \\
1.0 \times 10^{8}\end{array}$ & $\begin{array}{l}9.9 \times 10^{8} \\
1.0 \times 10^{7} \\
-\frac{1}{9.9} \times 10^{9} \\
8.2 \times 10^{7} \\
9.9 \times 10^{8}\end{array}$ & $\begin{array}{c}2.4 \times 10^{8} \\
-\frac{8.2 \times 10^{5}}{-}-\frac{1}{6.2 \times 10^{7}}-- \\
4.5 \times 10^{6} \\
3.0 \times 10^{7}\end{array}$ \\
\hline Clostridia* & $\begin{array}{l}3 \\
4 \\
5\end{array}$ & $\begin{array}{l}5.3 \times 10^{7} \\
5 \cdot 0 \times 10^{4} \\
2 \cdot 3 \times 10^{5}\end{array}$ & $\begin{array}{l}1.9 \times 10^{5} \\
6.1 \times 10^{5} \\
2.3 \times 10^{4}\end{array}$ & $\begin{array}{l}1.9 \times 10^{5} \\
6 \cdot 1 \times 10^{5} \\
2.3 \times 10^{5}\end{array}$ \\
\hline Enterococci $\dagger$ & $\begin{array}{l}1 \\
2 \\
4 \\
5\end{array}$ & $\begin{array}{l}\begin{array}{l}3 \cdot 0 \times 10^{7} \\
8.9 \times 10^{7}\end{array}-\frac{1}{-}-\frac{1}{10^{5}} \\
5 \cdot 0 \times 10^{3}\end{array}$ & $\begin{array}{l}5 \cdot 5 \times 10^{8} \\
7 \cdot 5 \times 10^{7} \\
--1-1 \\
2 \cdot 4 \times 10^{4} \\
8 \cdot 7 \times 10^{5}\end{array}$ & $\begin{array}{c}3 \cdot 3 \times 10^{6} \\
3 \cdot 7 \times 10^{6} \\
-\frac{1}{1 \cdot 9 \times 10^{4}} \\
5 \cdot 7 \times 10^{3}\end{array}$ \\
\hline Escherichia coli & $\begin{array}{l}1 \\
2 \\
3 \\
3 \\
4 \\
5\end{array}$ & $\begin{array}{c}7 \cdot 2 \times 10^{8} \\
5 \cdot 0 \times 10^{3} \\
-\frac{7}{1}-\frac{1}{0} \times 10^{8} \\
7 \cdot 1 \times 10^{4} \\
7 \cdot 7 \times 10^{6}\end{array}$ & $\begin{array}{l}1.0 \times 10^{8} \\
1.6 \times 10^{9} \\
-2-0=10^{6} \\
2.0 \times 10^{5} \\
5 \cdot 2 \times 10^{5} \\
9 \cdot 1 \times 10^{6}\end{array}$ & $\begin{array}{c}7 \cdot 7 \times 10^{6} \\
-\frac{1.0 \times 10^{7}}{2.0 \times 10^{6}}-- \\
\begin{array}{c}3.0 \times 10^{8} \\
1.0 \times 10^{7}\end{array}\end{array}$ \\
\hline Bacteroides & $\begin{array}{l}1 \\
2 \\
3 \\
3 \\
4 \\
5\end{array}$ & $\begin{array}{c}3.5 \times 10^{10} \\
5.0 \times 10^{7} \\
-\frac{-1}{5 \cdot 7 \times 10^{8}}- \\
5.0 \times 10^{6} \\
9.2 \times 10^{8}\end{array}$ & $\begin{array}{l}1 \cdot 0 \times 10^{11} \\
7 \cdot 5 \times 10^{6} \\
-1-9 \times 10^{9} \\
9 \cdot 9 \times 10^{7} \\
1 \cdot 3 \times 10^{7} \\
6 \cdot 1 \times 10^{6}\end{array}$ & $\begin{array}{c}7 \cdot 4 \times 10^{8} \\
7 \cdot 9 \times 10^{5} \\
-\frac{1}{5 \cdot 7 \times 10^{8}}-- \\
1 \cdot 3 \times 10^{7} \\
4 \cdot 3 \times 10^{8}\end{array}$ \\
\hline
\end{tabular}

* Clostridia were not isolated from patients no. 1 and no. 2.

$\uparrow$ Enterococci were not isolated from patient no. 3 . 
were much higher in the two patients who responded $\left(9.9 \times 10^{9}\right.$ per $\mathrm{g}$ and $7 \cdot 7 \times 10^{6}$ per g) than in the patient who failed to respond $\left(6 \cdot 6 \times 10^{4}\right.$ per g). In two patients (nos. 2 and 3), lactobacilli were not isolated from the faeces until lactulose was administered, and in one of these (no. 3) lactobacilli disappeared when therapy ceased. Patient 3 , and patients 4 and 5 in whom lactobacillus counts fell while on lactulose therapy, failed to respond clinically.

No other systematic relationship was demonstrated between changes in counts of organisms, lactulose therapy and clinical response of the patient. Counts of ammonia-producing organisms, e.g., Escherichia coli and Bacteroides spp. did not invariably fall during lactulose administration. Counts of $E$. coli decreased during lactulose therapy in one patient (no. 1) who responded clinically and in one (no. 3) who did not, and increased dramatically (from $5.0 \times 10^{3}$ to $1.6 \times 10^{9}$ per g) in another (no. 2) who responded clinically. Counts of Bacteroides spp. increased during lactulose therapy in one (no. 1) and decreased in the other (no. 2), both of whom responded clinically to lactulose.

During magnesium sulphate therapy the general tendency was for counts of organisms to fall. Both patients who responded to lactulose deteriorated whilst receiving magnesium sulphate, and counts of lactobacilli fell below that of the stabilisation period in one patient. The administration of neomycin to patient no. 5, after lactulose and magnesium sulphate therapy, eliminated $E$. coli from the faeces.

\section{Discussion}

Clinical response to lactulose is dependent on its breakdown to organic acids by bacteria and the consequent lowering of the colonic $p \mathrm{H}$, so some relationship might be expected between the effect of lactulose on the faecal flora and the clinical response of the patient. The beneficial effects of lactulose could arise (i) from fostering the growth of acidophilic organisms with consequent "displacement" of ammonia-producing species, (ii) from a reduction in the amount of ammonia produced by intestinal organisms at low $p \mathrm{H}$, or (iii) from a reduction in the amount of ammonia absorbed, because ammonia is effectively trapped in the gut at low $p \mathrm{H}$.

The reported effects of lactulose on the faecal flora are conflicting. Haenel, Muller-Beuthow and Scheunert (1957) and Haenel et al. (1958) found that generally the count of the bifidus group was not increased, and that counts of $E$. coli and streptococci were decreased. Bircher et al. (1969) reported an increase in numbers of anaerobic lactobacilli and a decrease in bacteroides counts after lactulose administration. Conn and Floch (1970) found that lactulose treatment resulted in moderate, but statistically insignificant, increases in the mean number of lactobacilli, a decrease in total aerobic bacteria and an increase in the total anaerobic flora.

The present results indicate that clinical improvement was not dependent upon drastic reductions in counts of ammonia-producing organisms. Counts of enterobacteria, considered to be among the most active ammonia producers (O'Grady, 1966), actually increased during some periods of lactulose therapy. Possibly it is not that the numbers of ammonia-producing organisms fall during 
lactulose administration, but that their production of ammonia and other toxic substances is inhibited; in our previous study, no correlation could be demonstrated between faecal counts of ammonia-producing species and concentrations of ammonia in the blood and faeces of the subjects studied (Zeegen et al., 1970).

Nor could clinical improvement be related in the present analysis to the highest count of lactobacilli recorded - a higher count was recorded for a non-responding patient than for one who responded. Perhaps there is no absolute lactobacillus count that must be exceeded in all patients for symptomatic improvement to occur, but each individual may have a threshold count above which improvement follows. The amount of acid produced, and hence the decrease in colonic $p \mathrm{H}$ on which the beneficial effect of lactulose presumably depends is likely to be related to the total increase in numbers of lactobacilli. In the non-responding patient in whom an increase in the lactobacillus count occurred during lactulose therapy, the highest count reached was only $6.6 \times 10^{4}$ per g. Such a count represents only a tiny fraction of the total fiora, and the influence of this component on the remainder of the flora and its environment is likely to be correspondingly small.

\section{SUMmaRY}

The changes that occurred in the faecal flora during the separate administration of lactulose and magnesium sulphate were studied in five patients with hepatic encephalopathy. Lactulose therapy produced significant increases in lactobacillus counts in three patients, and two of these patients showed clinical improvement. No systematic change occurred in the counts of other organisms during either treatment; in particular it was not possible to correlate clinical improvement with a reduction in the count of the two groups of organismsenterobacteria and Bacteroides spp.- that are considered to be most active in the production of ammonia.

\section{REFERENCES}

Bircher, J., Scollo-lavizzari, G., Hoffmann, K. and Haemmerli, U. P. 1969. Die Behandlung der chronischen porto-systemischen Enzephalopathie mit Laktulose. Schwiez. med. Wschr., 99, 584.

Conn, H. O. AND Floch, M. H. 1970. Effects of lactulose and Lactobacillus acidophilus on the faecal flora. Am. J. clin. Nutr., 23, 1588.

DAHLQVIST, A. AND GRYBOSKI, J. D. 1965. Inability of human small-intestinal lactase to hydrolyse lactulose. Biochim. biophys. Acta, 110, 635.

Elkington, S. G., Floch, M. H. and ConN, H. O. 1969. Control of chronic portalsystemic encephalopathy by lactulose. Gut, 10, 416.

FUNG, W. P. AND KHoо, O. T. 1968. Treatment of chronic hepatic encephalopathy with lactulose. Med. J. Aust., 2, 160.

Goldsmith, P. L. 1965. Programme modification. Program ICI/A/10705/9, ICI Computer Library.

Haenel, H., Feldheim, W., Muller-Beuthow, W. and Ruttloff, H. 1958. Versuche zur Umstimmung der faecalen Flora des gesunden Erwachsenen. Zentbl. Bakt. ParasitKde, 1 Abt. Orig., 173, 76. 
Haenel, H., Muller-Beuthow, W. and Scheunert, A. 1957. Der Einfluss extremer Kostformen auf die faecale Flora des Menschen. II. Mitterlung. Zentbl. Bakt. ParasitKde, 1 Abt. Orig., 169, 45.

Hamilton, J. D., Dyer, N. H., Dawson, A. M., O'Grady, F. W., Vince, A., Fenton, J. C. B. AND MolLIN, D. L. 1970. Assessment and significance of bacterial overgrowth in the small bowel. Q. Jl Med., 39, 265.

Hoffmann, K., Mossel, D. A. A., Korus, W. and Kamer, J. H. van de 1964. Untersuchungen uber die Wirkungsweise der Lactulose ( $\beta$-Galactosido-Fructose) im Darm. Klin. Wschr., 42, 126.

Ma, M. H., McLeod, J. G. ANd BlackbuRn, C. R. B. 1969. Long term treatment of chronic portal systemic encephalopathy with lactulose. Australas. Ann. Med., 18, 117.

O'Grady, F. W. 1966. Differences in ammonia production by faecal bacteria of patients with hepatic encephalopathy. Proc. R. Soc. Med., 59, 1246.

Zeegen, R., Drinkwater, J. E., Fenton, J. C. B., Vince, A. ANd Dawson, A. M. 1970. Some observations on the effects of treatment with lactulose on patients with chronic hepatic encephalopathy. Q. Jl Med., 39, 245. 